\title{
Osteoporosis Delimit the Indication for Additional Fixation in Oblique Lumbar Interbody Fusion
}

\author{
Kaiwen Cai \\ Affiliated Hospital of Medical School Ningbo University and Ningbo City Third Hospital \\ Kefeng Luo \\ Affiliated Hospital of Medical School Ningbo University and Ningbo City Third Hospital \\ Jinjin Zhu \\ Zhejiang University School of Medicine Sir Run Run Shaw Hospital \\ Kai Zhang \\ Affiliated Hospital of Medical School Ningbo University and Ningbo City Third Hospital \\ Shengkai Yu \\ Ningbo University Medical School \\ Yi Ye \\ Affiliated Hospital of Medical School Ningbo University and Ningbo City Third Hospital \\ Guoqiang Jiang ( $\nabla$ jiangguoqiang@nbu.edu.cn ) \\ Affiliated Hospital of Medical School Ningbo University and Ningbo City Third Hospital
}

\section{Research article}

Keywords: Osteoporosis, additional fixation, oblique lumbar, interbody fusion

Posted Date: January 20th, 2021

DOI: https://doi.org/10.21203/rs.3.rs-149538/v1

License: (c) (i) This work is licensed under a Creative Commons Attribution 4.0 International License. Read Full License 


\section{Abstract}

Study design: A retrospective cohort study.

Objective: To detect the boundary of indications of fixation in OLIF surgery.

Methods: Review patients undergoing stand-alone or combined OLIF. Measure the disc height increment ( $\triangle \mathrm{DH})$, foraminal height (FH), cage subsidence (CS). VAS and the ODI was used to evaluate low back pain and functionality. Multiple linear regression were used to determine the risk factors of CS.

Results: A totle of 66 consecutive patients included. The BMD in combined group was significantly lower than that of stand-alone group( $\mathrm{p}=0.005)$. The combined group showed better FH maintenance at 6 months $(p=0.049)$ and last follow-up $(p=0.019)$. In combined group, tCS was significantly lower at all post-operation point $(p \leq 0.001)$. BMD was a mild negative correlated factor for $C S$ in combined group $(r=-0.602, p=0.001)$ and a strongly negative correlated factor in stand-alone group $(r=-0.797, p<0.001)$. Greater mCS significantly associated with worse VAS $(r=0.685, p<0.001)$ and ODI $(r=0.616$, $p<0.001)$ in stand-alone group, and this effect was significantly weakened in the combined group as VAS $(r=0.427, p=0.033)$ and ODI $(r=0.594, p=0.002)$. Patients with stand-alone OLIF were at risk of severe CS when BMD $<-1.38$, while those with combined OLIF had an equal risk when BMD $<-4.77$.

Conclusions: The long-term fusion rates and functionality improvements of OLIF with or without fixation are comparable. Patients with BMD < -1.38 may not suitable for stand-alone procedure due to higher risk of severe CS and worse clinical outcomes. Additional fixation can extends the applicable boundary to $\mathrm{BMD}=-4.77$.

\section{Background}

Oblique lumbar interbody fusion (OLIF) has become a popular indirect decompression and interbody fusion technique in the last decade. It was developed from anterior lumbar interbody fusion (ALIF) ${ }^{[1]}$ and direct lateral interbody fusion (DLIF)/extreme lateral interbody fusion (XLIF) ${ }^{[2-3]}$, and it improved the technical characteristics of these procedures. The rudiment of the OLIF operation method was described by Dr. Mayer ${ }^{[4]}$ in 1997 , who established a working channel between the left psoas major muscle and the abdominal vascular sheath and completed intervertebral fusion via this channel. The first case series of this method was reported in detail by Silvestre in 2012, and the method was officially named OLIF ${ }^{[5]}$. The advantage of OLIF is that it avoids invasion of the peritoneum during the ALIF procedure, and compared with DLIF/XLIF, OLIF uses the natural space between the psoas major and vascular sheath to enter the target area without the need for cutting the psoas major muscle, thus avoiding the potential risk of lumbar plexus injury and bleeding; additionally, the incidence of postoperative hip flexion weakness and thigh numbness is also lower ${ }^{[6]}$.

However, some surgical-related complications of OLIF have been reported. The overall incidence of complications is reported to be $11.2-48.3 \%$, including fatal abdominal aorta/iliac artery injury, segmental artery injury, peritoneal injury, lumbar myasthenia, ureteral injury, spinal nerve injury, sympathetic nerve injury, incision pain, cage subsidence (CS)/retropulsion, infection, retrograde ejaculation, etc. ${ }^{[5-8]}$. Among these complications, CS is considered to be significantly related to worse clinical outcomes ${ }^{[9]}$. Existing studies seem to suggest a non-neglectable incidence of $\mathrm{CS}^{[7,9,10-11]}$. To avoid this complication, anterolateral screw fixation or posterior percutaneous pedicle screw fixation was introduced in the OLIF procedure, resulting in combined OLIF. This additional implantation disperses the stress transfer of the cage and protects the endplate; it also increases the operation time, medical cost, intraoperative bleeding amount and invasion of paraspinal tissue. At present, the evidence for whether or when additional fixation is needed is mixed. Generally, the following are risk factors for CS: endplate injury, osteoporosis, grade II spondylolisthesis and above, isthmic spondylolisthesis and multilevel fusion. Patients with the risk factors listed above are considered to be in need of additional implantation ${ }^{[6]}$. However, the above opinions are based on experience and a lack of reliable evidence and quantitative criteria for fixation indications.

The purpose of this study was to detect the risk factors for CS in OLIF and to provide the boundary of indications for the use of additional implantation through a double-center retrospective cohort study of stand-alone OLIF and combined OLIF.

\section{Methods And Materials Patient selection}

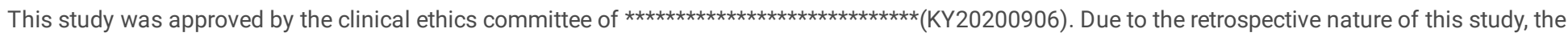
written informed consent of patients was waived. From June 2017 to December 2019, 96 consecutive patients underwent OLIF surgery in two centers, either stand-alone or combined OLIF. The inclusion criteria were as follows: 1. patients who met the indications for OLIF surgery, 2. ineffective conservative treatment for more than 3 months, 3. Patients who underwent OLIF surgery with or without additional implantation, and 4. patients who had chronic low back pain with or without radiating pain in the lower limbs. The exclusion criteria were as follows: 1. OLIF combined with direct

decompression, 2. patients with incomplete radiological data, 3. patients who were lost to follow-up or had incomplete follow-up records, and 4. a change in the implantation method for revision surgery.

\section{Surgical procedure}


All surgeries were performed by senior spine surgeons with more than 20 years of experience and their team. Generally, after general anesthesia, the patient was fixed in the right lateral decubitus position and disinfected. After the target segment was confirmed by $\mathrm{C}$-arm fluoroscopy, a $5 \mathrm{~cm}$ skin incision was made on the lateral abdomen. The external oblique, internal oblique and transversalis were incised along the muscle fiber direction, and the retroperitoneal fat was separated with the fingers to reach the left anterolateral part of the target intervertebral space. Then, the psoas major muscle was pushed back, and major vessels, peritoneal contents and the ureter were pushed forward gently. The guide wire was inserted, and sequential dilation was achieved with a retractor. A $1.5 \mathrm{~cm}$ incision was made on the left anterolateral annulus fibrosus of the target disc to remove the nucleus pulposus and prepare the endplate. An appropriately sized cage was filled with allogeneic bone and implanted into the intervertebral space. Again, C-arm fluoroscopy confirmed that the position of the cage was correct. In patients who underwent combined OLIF, additional percutaneous pedicle screw fixation of the cephalic and caudal vertebrae of the target segment was performed as described in previous studies ${ }^{[12-13]}$. No direct decompression of the spinal canal was performed in any of the patients.

After the operation, all patients received nonsteroidal drugs, muscle relaxants and neurotrophic drugs. Lumbar and leg muscle training were conducted under the guidance of physiotherapists. In addition, patients with bone mineral density (BMD) values between -1.5 and -2.5 received calcium and vitamin $\mathrm{D}$, while patients with $\mathrm{BMD}$ values lower than -2.5 received bisphosphonates in addition to the above drugs.

\section{Clinical outcome data collection}

Age, gender, body mass index (BMI) and T-score of lumbar BMD in all included patients were recorded as baseline characteristics. BMD was measured by dual energy X-ray absorptiometry (DEXA), and the T-score was the BMD compared to the normal mean. The visual analog scale (VAS) ${ }^{[14]}$ was used to evaluate low-back pain, which was recorded preoperatively and 3 days, 3 months, and 6 months postoperatively as well as at the last follow-up. The Oswestry disability index (ODI) ${ }^{[15]}$ was used to evaluate functionality and was recorded preoperatively and at 3 months and 6 months postoperatively as well as at the last follow-up. Surgical-related complications were documented.

\section{Radiography data measurement}

The radiography measurements and interbody fusion evaluations of all patients were evaluated by sagittal lumbar computed tomography. We measured the preoperative and postoperative disc height $(\mathrm{DH})$ of each patient's target segment. The $\mathrm{DH}$ was defined as the mean height of the anterior, middle, and posterior heights of the intervertebral space (Fig. 1). The $\triangle \mathrm{DH}$ was defined as the postoperative $\mathrm{DH}$ minus the preoperative $\mathrm{DH}$, which represents the increment in the height of the intervertebral space. The foraminal height (FH) was measured perpendicular from the lower edge of the cephalic vertebral pedicle to the upper edge of the caudal vertebral pedicle, and the mean FH value was used to evaluate the effect of indirect decompression. The total cage subsidence (tCS) was calculated as the sum of cephalic and caudal subsidence (Fig. 1). Since the tCS is composed of two variable whose length is opposite to that of the cephalic and caudal, thus, the one with the larger value is considered as the main cage subsidence (mCS). The FH was measured

preoperatively and 3 months and 6 months postoperatively as well as at the last follow-up. CS was measured 3 months and 6 months after the operation as well as at the last follow-up. A case where a cage retreated more than $2 \mathrm{~mm}$ at any time point was considered cage retropulsion. The evaluation of fusion 6 months after the operation and at the last follow-up was performed using the Bridwell interbody fusion grading system ${ }^{[16]}$. If grade I or grade II was reached, the occurrence of interbody fusion was considered. All imaging data were independently and blindly evaluated by two senior radiologists. Controversial measurement results were alleviated by consensus .

\section{Statistical analysis}

SPSS 23.0 software (IBM Co., Armonk, NY, USA) was used to analyze the data. A one-sample K-S test was used to check the normality of the measurement data, and the mean $\pm S D$ was used if normality was met. If the data did not obey a normal distribution, we described the variables as $M\left[Q_{1}\right.$, $\mathrm{Q}_{3}$ ], and the Wilcoxon Mann-Whitney test was used. Fisher's exact probability method was used to compare the enumeration data between groups. For correlation analysis, linear regression and multiple linear regression analyses were used. Severe CS is considered to occur when $\mathrm{mCS}>4 \mathrm{~mm}{ }^{[17]}$. The test standard was set as $\mathrm{a}=0.05$, and differences were considered statistically significant with a $\mathrm{p}$ value $<0.05$.

\section{Results}

\section{Patient selection}

The case records of 94 patients who underwent OLIF were reviewed, and as a result, a total of 66 patients were included. The average follow-up period was $22.6 \pm 6.6$ months (range 13-34 months). Among the 66 patients included, 41 patients who received stand-alone OLIF were set as the stand-alone group, and 25 patients who received OLIF combined with percutaneous pedicle screw fixation were set as the combined group. Among the 28 excluded patients, 17 were lost to follow-up or had incomplete follow-up data, 8 had incomplete radiography data, and 3 were withdrawn from the cohort because of secondary pedicle screw fixation after primary stand-alone surgery due to unbearable low back pain. The demographic baseline characteristics of the patients in both groups are described in Table 1. There was no significant difference in age, sex or BMI between the two groups, but the BMD in the combined group was significantly lower than that in the stand-alone group $(-1.9 \pm 1.3 \mathrm{vs}-0.9 \pm 1.4, p=0.005)$, which also reflected the surgeon's preference for the selection of a fixation scheme for patients with a low BMD (Table 1).

Page 3/9 
Table 1

Baseline characteristics of included patients

\begin{tabular}{|llll|}
\hline Baseline data & $\begin{array}{l}\text { Combined } \\
(\mathbf{n}=\mathbf{2 5})\end{array}$ & $\begin{array}{l}\text { Stand-alone } \\
(\mathbf{n}=\mathbf{4 1})\end{array}$ & P value \\
\hline Age $(\mathrm{y})$ & $62.16 \pm 8.65$ & $59.46 \pm 8.46$ & 0.217 \\
\hline Gender(M/F) & $12 / 13$ & $22 / 19$ & 0.800 \\
\hline BMl(kg/m2) & $24.32 \pm 1.59$ & $24.33 \pm 2.40$ & 0.984 \\
\hline BMD(T value) & $-1.9 \pm 1.3$ & $-0.9 \pm 1.4$ & $0.005^{\star}$ \\
\hline
\end{tabular}

BMI: body mass index, BMD: bone mineral density. * The difference was statistically significant $(p<0.05)$

\section{Clinical outcomes}

Before surgery, there was no significant difference in the VAS $(6[5.5,7]$ vs $6[5.5,7], p=0.826)$ or ODI $(62.22[53.33,68.89]$ vs $57.78[53.33,64.44], p=$ 0.551) scores between the combined group and stand-alone group. The postoperative VAS and ODI scores decreased significantly in each group and were well maintained 3 months and 6 months after surgery as well as at the last follow-up. Postoperatively, the VAS score of the stand-alone group was slightly better than that of the combined group $(3[3,4]$ vs $4[3,5], p=0.012)$. However, the VAS score in the combined group was better than that in the stand-alone group 3 months after the operation $(3[1.5,3]$ vs $3[2,4], p=0.038)$. The difference disappeared 6 months after the operation and at the last follow-up. There was no significant difference in ODI scores between the groups at any of the time points (Table 2, Fig. 2).

Table 2

Clinical out-comes of the two groups.

\begin{tabular}{|c|c|c|c|c|c|c|c|c|c|}
\hline \multirow[t]{2}{*}{ Groups } & \multicolumn{5}{|c|}{ VAS score } & \multicolumn{4}{|l|}{ ODI(\%) } \\
\hline & Pre-op & $\begin{array}{l}\text { Post- } \\
\text { op }\end{array}$ & $3 \mathrm{~m}$ & $6 \mathrm{~m}$ & $\begin{array}{l}\text { Last f- } \\
\mathbf{u}\end{array}$ & Pre-op & $3 \mathrm{~m}$ & $6 \mathrm{~m}$ & Last f-u \\
\hline Combined & $\begin{array}{l}6[5.5, \\
7]\end{array}$ & $4[3,5]$ & $\begin{array}{l}3[1.5 \\
3]\end{array}$ & $2[2,3]$ & $\begin{array}{l}2[1.5, \\
2]\end{array}$ & $\begin{array}{l}62.22[53.33, \\
68.89]\end{array}$ & $\begin{array}{l}\text { 24.44 [17.78, } \\
28.89]\end{array}$ & $\begin{array}{l}\text { 17.78 [15.56, } \\
20.00]\end{array}$ & $\begin{array}{l}15.56[13.33, \\
17.78]\end{array}$ \\
\hline $\begin{array}{l}\text { Stand- } \\
\text { alone }\end{array}$ & $\begin{array}{l}6[5.5, \\
7]\end{array}$ & $3[3,4]$ & $3[2,4]$ & $2[2,3]$ & $2[2,3]$ & $\begin{array}{l}57.78[53.33 \\
64.44]\end{array}$ & $\begin{array}{l}26.67[18.89 \\
38.89]\end{array}$ & $\begin{array}{l}20.00[16.67 \\
22.22]\end{array}$ & $\begin{array}{l}15.56[13.33, \\
21.11]\end{array}$ \\
\hline$Z$ value & -0.229 & -2.528 & -2.075 & -1.657 & -1.823 & -0.603 & -1.348 & -1.134 & -0.960 \\
\hline$P$ value & 0.826 & $0.012^{\star}$ & $0.038 *$ & 0.100 & 0.067 & 0.551 & 0.180 & 0.260 & 0.341 \\
\hline
\end{tabular}

\section{Radiography outcomes}

In general, the $\mathrm{DH}$ increased by $3.11[2.12,4.45] \mathrm{mm}$ after the operation, but there was no significant difference in the $\Delta \mathrm{DH}$ between the two groups $(\mathrm{p}=$ 0.848). The FH values preoperatively and 3 postoperatively were comparable between the two groups. The combined group showed good FH maintenance, and the stand-alone group had more obvious FH loss. There was a significant difference of FH between the two groups 6 months after the operation $(18.37 \pm 1.98$ vs $17.26 \pm 2.29, p=0.049)$, and the difference was more significant at the last follow-up $(18.22 \pm 2.00 \mathrm{vs} 16.87 \pm 2.34, p=0.019)$. The combined group had significantly lower tCS than the stand-alone group at all time points after the operation (all $p \leq 0.001$ ). There was no significant difference in the fusion rate between the two groups 6 months after the operation or at the last follow-up $(92 \%$ vs $90.2 \%, 100 \%$ vs $95.1 \%$, respectively) (Table 3, Fig. 2). 
Table 3

Radiological results the two groups.

\begin{tabular}{|c|c|c|c|c|c|c|c|c|c|c|c|}
\hline \multirow[t]{2}{*}{ Groups } & \multirow{2}{*}{$\begin{array}{l}\Delta \mathrm{DH} \\
(\mathrm{mm})\end{array}$} & \multicolumn{5}{|l|}{$\mathrm{FH}(\mathrm{mm})$} & \multicolumn{3}{|l|}{$\mathrm{tCS}(\mathrm{mm})$} & \multicolumn{2}{|l|}{ Fusion rate } \\
\hline & & Pre-op & Post-op & $3 \mathrm{~m}$ & $6 \mathrm{~m}$ & $\begin{array}{l}\text { Last f- } \\
\mathrm{u}\end{array}$ & $3 \mathrm{~m}$ & $6 \mathrm{~m}$ & Last f-u & $6 \mathrm{~m}$ & Last f-u \\
\hline Combined & $\begin{array}{l}3.24 \\
{[2.03,} \\
4.55]\end{array}$ & $\begin{array}{l}17.18 \pm \\
2.39\end{array}$ & $\begin{array}{l}19.40 \pm \\
2.00\end{array}$ & $\begin{array}{l}18.71 \\
\pm 2.10\end{array}$ & $\begin{array}{l}18.37 \\
\pm 1.98\end{array}$ & $\begin{array}{l}18.22 \\
\pm 2.00\end{array}$ & $\begin{array}{l}2.50 \pm \\
1.24\end{array}$ & $\begin{array}{l}3.20 \pm \\
1.48\end{array}$ & $\begin{array}{l}3.50 \pm \\
1.50\end{array}$ & $23 / 25(92 \%)$ & $25 / 25(100 \%)$ \\
\hline $\begin{array}{l}\text { Stand- } \\
\text { alone }\end{array}$ & $\begin{array}{l}3.08 \\
{[2.15,} \\
4.33]\end{array}$ & $\begin{array}{l}17.31 \pm \\
2.14\end{array}$ & $\begin{array}{l}19.87 \pm \\
1.93\end{array}$ & $\begin{array}{l}18.36 \\
\pm 2.41\end{array}$ & $\begin{array}{l}17.26 \\
\pm 2.29\end{array}$ & $\begin{array}{l}16.87 \\
\pm 2.34\end{array}$ & $\begin{array}{l}4.15 \pm \\
1.91\end{array}$ & $\begin{array}{l}4.85 \pm \\
2.03\end{array}$ & $\begin{array}{l}5.26 \pm \\
2.11\end{array}$ & $37 / 41(90.2 \%)$ & $39 / 41(95.1 \%$ \\
\hline $\begin{array}{l}\text { Statistical } \\
\text { value }\end{array}$ & $Z=-0.192$ & $t=-0.226$ & $t=-0.955$ & $\begin{array}{l}t= \\
0.599\end{array}$ & $\begin{array}{l}\mathrm{t}= \\
2.004\end{array}$ & $\begin{array}{l}\mathrm{t}= \\
2.397\end{array}$ & $t=-3.837$ & $t=-3.522$ & $t=-3.641$ & 1 & 1 \\
\hline$P$ value & 0.848 & 0.822 & 0.343 & 0.551 & $0.049 *$ & $0.019 *$ & $<0.001 *$ & $0.001^{\star}$ & $0.001 *$ & 1.000 & 0.522 \\
\hline
\end{tabular}

\section{Correlation analysis}

Because the correlation between CS and clinical outcomes depends mainly on the severity of individual CS rather than the sum. Thus, we use linear regression to analyze the relationship between mCS and BMD, BMI, DH, VAS, ODI. In the combined group, BMD was mildly negatively correlated ( $r=$ $-0.602, p=0.001)$ with $\mathrm{mCS}$, and BMI was a moderate-intensity positive correlation for $\mathrm{mCS}(r=0.400, p=0.047)$, while $\Delta \mathrm{DH}(r=-0.059, p=0.781)$ were not significantly correlated with mCS. In contrast, in the stand-alone group, the negative correlation between BMD and mCS was significantly enhanced $(r=$ $-0.797, p<0.001)$, and a correlation between mCS and BMI $(r=0.207, p=0.195)$ or $\triangle \mathrm{DH}(r=0.271, p=0.086)$ was not found.

Multiple linear regression showed that only BMD was a risk factor for mCS in the regression model in the combined group $(\beta=-0.535, p=0.005)$ and stand-alone group $(\beta=-0.756, p<0.001)$ (Table 4). Therefore, $B M I$ and $\triangle D H$ were excluded from the multiple linear regression model, and a simple linear regression model of BMD and $\mathrm{mCS}$ was used(Table 5). According to the linear regression model, when severe CS was defined as $\mathrm{mCS}>4 \mathrm{~mm}$, the $\mathrm{BMD}$ threshold in the stand-alone group was -1.38 , and the use of additional implantation expanded the BMD threshold to -4.77 in the combined group.

Table 4

Multiple linear regression results

\begin{tabular}{|c|c|c|c|c|c|}
\hline Groups & Variables & SE & $\beta$ & $95 \% \mathrm{Cl}$ & $P$ value \\
\hline \multirow[t]{4}{*}{ Combined } & Constant & 3.003 & & $(-9.539,2.950)$ & 0.285 \\
\hline & BMD & 0.156 & -0.535 & $(-0.812,-0.164)$ & $0.005^{\star}$ \\
\hline & $\mathrm{BMI}$ & 0.125 & 0.268 & $(-0.063,0.457)$ & 0.130 \\
\hline & $\Delta \mathrm{DH}$ & 0.085 & -0.002 & $(-0.177,0.176)$ & 0.992 \\
\hline \multirow[t]{4}{*}{ Stand-alone } & Constant & 1.528 & & $(-3.688,2.505)$ & 0.701 \\
\hline & BMD & 0.102 & -0.756 & $(-1.031,-0.618)$ & $<0.001$ * \\
\hline & BMI & 0.060 & 0.185 & $(-0.002,0.240)$ & 0.054 \\
\hline & $\Delta \mathrm{DH}$ & 0.084 & 0.177 & $(-0.013,0.329)$ & 0.069 \\
\hline
\end{tabular}

Table 5

Simple linear regression results.

\begin{tabular}{|llllll|}
\hline Groups & Variables & SE & $\boldsymbol{\beta}$ & $\mathbf{9 5 \%} \mathrm{Cl}$ & P value \\
\hline Combined & Constant & 0.342 & & $(0.675,2.090)$ & $0.001^{*}$ \\
\cline { 2 - 5 } & BMD & 0.152 & -0.602 & $(-0.862,-0.234)$ & $0.001^{*}$ \\
\hline Stand-alone & Constant & 0.174 & & $(2.451,3.153)$ & $<0.001^{*}$ \\
\cline { 2 - 5 } & BMD & 0.106 & -0.797 & $(-1.083,-0.656)$ & $<0.001^{*}$ \\
\hline
\end{tabular}

Dependent variable: mCS, SE: standard error, $95 \% \mathrm{Cl}$ : $95 \%$ confidence interval, * The difference was statistically significant $(p<0.05)$ 
On the other hand, there was only a low to moderate positive correlation between mCS and VAS $(r=0.427, p=0.033)$ or ODI $(r=0.594, p=0.002)$ scores in the combined group. In contrast, in the stand-alone group, this positive correlation was much stronger with VAS $(r=0.685, p<0.001)$ and DOI $(r=0.616, p$ $<0.001)$.

\section{Complications}

No cases of major artery injury or spinal nerve injury occurred. One case of segmental artery injury occurred in the stand-alone group, and lumbar myasthenia was relatively more common, with 4 cases occurring in each group. There were 3 cases of sympathetic nerve injury in the combined group and 2 cases in the stand-alone group. There was 1 case of ureteral injury in the stand-alone group. No cage retropulsion or other complications were observed in either group. Statistical analysis was abandoned due to the small number of complications.

\section{Discussion}

As a kind of anterolateral fusion, the decompression effect of OLIF is indirect, which also leads to the limitation of surgical indications. Generally, the surgical indications of OLIF are lumbar spondylolisthesis below grade II, lumbar disc herniation combined with segmental instability, nerve root canal stenosis caused by loss of disc height, degenerative scoliosis/kyphosis, and degenerative disc disease ${ }^{[18]}$. The absolute contraindications include access channel stenosis, retroperitoneal adhesion, lumbar spondylolisthesis grade III or above, severe spinal stenosis or intraspinal lesions. The relative contraindications are L1-2 segment renal artery and vein interference and L5-S1 iliac vessel occlusion ${ }^{[19-20]}$. Therefore, patients with lumbar instability or mild spondylolisthesis without severe spinal stenosis have a better and more minimally invasive choice of fusion.

To pursue the minimally invasive advantage of OLIF, stand-alone OLIF is widely used, as it has a shorter operation time and less intraoperative bleeding than other operations and does not invade the posterior structure ${ }^{[21]}$. However, this kind of fusion method is controversial due to its potential stability defects. Guo Hz et al. ${ }^{[22]}$ found that the stability of stand-alone OLIF was significantly worse than that of additional pedicle screw fixation through finite element analysis. In contrast, St Clair s et al. ${ }^{[23]}$ proved that the stability, overall stiffness and failure load of stand-alone OLIF were similar to those of pedicle screw rod fixation systems through biomechanical testing of the human spine in vitro. In clinical studies, the comparison results of stand-alone OLIF and combined OLIF have also been inconsistent. In some studies, the short-term clinical results of stand-alone OLIF were better ${ }^{[9,24]}$, but in other studies, the complication rate of stand-alone OLIF was significantly higher than that of combined OLIF[10-11]. In terms of the indications for additional implantation, some studies have only empirically suggested that patients with a BMD $<-1$ should undergo pedicle screw fixation to prevent subsidence ${ }^{[25]}$. Other authors believe that additional fixation may be required for patients with a $\mathrm{BMD}<-2.5$ or who with $\mathrm{BMI} \geq 30 \mathrm{~kg} / \mathrm{m}^{2[26]}$. At present, there is no consensus on when additional implantation is needed in OLIF surgery.

Obviously, before bony fusion, stiff support will transfer more gravity load between vertebrae than soft disc tissue. Although the cages used in OLIF are larger than traditional cages, the stress shielding effect is still almost unavoidable in stand-alone fusion ${ }^{[27]}$. Excessive stress leads to local collapse of the endplate followed by repeated trabecular microfractures under the endplate in daily activities and causes intractable pain ${ }^{[28]}$. This process gradually stops until the occurrence of curvature coincidence, sub-endplate osteosclerosis and intervertebral fusion.

In this study, we found a strong negative correlation between BMD and CS, indicating that osteoporosis patients are more prone to the occurrence of CS. The correlation analysis also confirmed a correlation between a larger mCS and worse VAS and ODI scores. In the combined group, additional implantation showed an obvious anti-subsidence effect, which led to significant pain improvement advantages 3 months after the operation. The ephemeral inferiority in VAS scores 3 days after surgery in the combined group may be caused by additional posterior surgical trauma. From 6 months to the last follow-up, because interbody fusion was achieved in the majority of patients in both groups, the unstable factors of the intervertebral space were eliminated, induce the difference in pain improvement between the groups disappeared. In terms of functionality improvements, although the ODI scores in the combined group were always slightly better than those in the stand-alone group, there was no significant difference between the two groups.

The correlation analysis showed that osteoporosis was a risk factor for mCS. According to the linear regression equations obtained in this study, patients who underwent the stand-alone method were at risk of severe CS ( $>4 \mathrm{~mm}$ ) when their BMD was $<-1.38$. When combined OLIF was adopted, only patients with a BMD $<-4.77$ were at equal risk to those who underwent the stand-alone method. In this study, BMI did not show a correlation with mCS in any group, which may be because, on the one hand, greater BMI will increase vertebral load as a risk factor, and on the other hand, greater BMI is a protective factor for osteoporosis in postmenopausal women ${ }^{[29-30]}$. In addition, it seemed that there was no correlation between the extent of intervertebral space expansion (i.e., $\triangle \mathrm{DH}$ ) and mCS. Based on our data, we believe that the retraction force of the paravertebral ligament is almost negligible compared with the weight load. Previously, Oh kW et al ${ }^{[31]}$ proved that there was no correlation between CS and clinical results after PLIF surgery. Similarly, we also found that additional implantation could prevent the low back pain caused by tCS/mCS, and the correlation between low back pain and tCS/mCS was significantly weakened in the combined group. These results demonstrated the effect of interbody stabilization on pain relief.

The limitations of this study are as follows. 1. The sample size included in this study was still small, which may have caused bias in the multiple regression analysis. 2. The BMD T values were obtained before treatment, so the effect of antiosteoporosis treatment was ignored during the follow-up, which may have resulted in an underestimation of subsidence. 3. Three patients with severe low back pain were excluded from the stand-alone cohort due to secondary fixation, which may have led to the underestimation of adverse results in the stand-alone group. 
In conclusion, a low BMD is a risk factor for CS in OLIF, and CS is associated with worse postoperative low back pain. We suggest that patients with a $\mathrm{BMD}<-1.38$ who undergo stand-alone OLIF may face a greater risk of CS and worse clinical outcomes. Additional implantation extends the applicable boundary with the same risk to a BMD $=-4.77$ and may avoid adverse clinical outcomes to a certain extent.

\section{Abbreviations}

OLIF: oblique lumbar interbody fusion; ALIF: anterior lumbar interbody fusion; DLIF: direct lateral interbody fusion; XLIF: extreme lateral interbody fusion; CS: cage subsidence; BMD: bone mineral density; BMI: body mass index; DEXA: dual energy X-ray absorptiometry; VAS: visual analog scale; ODI: oswestry disability index; $\mathrm{DH}$ : disc height; $\triangle \mathrm{DH}$ : disc height increment; $\mathrm{FH}$ : foraminal height; tCS: total cage subsidence; mCS: main cage subsidence;

\section{Declarations}

\section{Acknowlegements}

The authors thank Professor Xiangqian Fang's team from the Department of Orthopaedic of Sir Run Run Shaw Hospital for their cooperation in this study.

\section{Authors' contributions}

KC and KZ: quantification and data gathering. GJ: hypothesis and study design. KC, JZ and SY: data analysis. KC and KL: writing and editing. YY: Data maintenance and management. All authors contributed in the final revision of the draft. The authors read and approved the final manuscript.

\section{Funding}

Not applicable.

\section{Availability of data and materials}

The datasets used and/or analyzed during the current study are available from the corresponding author on reasonable request.

\section{Ethics approval and consent to participate}

The study protocol was approved by the clinical ethics committee of the affiliated hospital of medical school of Ningbo university(KY20200906), Ningbo, China.

\section{Consent for publication}

Not applicable

\section{Competing interests}

All authors have no conflicts of interest to disclose.

\section{Conflicts of Interest}

All authors have no conflicts of interest to disclose.

\section{References}

1. SACKS S. ANTERIOR INTERBODY FUSION OF THE LUMBAR SPINE. J Bone Joint Surg Br. 1965;47:211-223.

2. Ozgur BM, Aryan HE, Pimenta L, Taylor WR. Extreme Lateral Interbody Fusion (XLIF): a novel surgical technique for anterior lumbar interbody fusion. Spine J. 2006;6(4):435-443.

3. Knight RQ, Schwaegler P, Hanscom D, Roh J. Direct lateral lumbar interbody fusion for degenerative conditions: early complication profile. J Spinal Disord Tech. 2009;22(1):34-37.

4. Mayer H M. A new microsurgical technique for minimally invasive anterior lumbar interbody fusion. Spine, 1997, $22(6): 691$.

5. Silvestre C, Mac-Thiong J M, Hilmi R, et al. Complications and Morbidities of Mini-open Anterior Retroperitoneal Lumbar Interbody Fusion: Oblique Lumbar Interbody Fusion in 179 Patients. Asian Spine Journal, 2012, 6(2):89-97.

6. Li R, Li X, Zhou H, Jiang W. Development and Application of Oblique Lumbar Interbody Fusion. Orthop Surg. 2020;12(2):355-365.

7. Abe K, Orita S, Mannoji C, et al. Perioperative Complications in 155 Patients Who Underwent Oblique Lateral Interbody Fusion Surgery: Perspectives and Indications From a Retrospective, Multicenter Survey.[J]. Spine, 2017, 42(1):55-62.

8. Miller C, Gulati P, Bandlish D, et al. Prepsoas oblique lateral lumbar interbody fusion in deformity surgery.[J]. Ann Transl Med. 2018, 6(6):108-108.

9. He W, He D, Sun Y, et al. Standalone oblique lateral interbody fusion vs. combined with percutaneous pedicle screw in spondylolisthesis. BMC Musculoskelet Disord. 2020;21(1):184. Published 2020 Mar 23. 
10. Liu JP, Wang Q, Feng HL, et al. Clinical analysis of the complications of oblique lateral interbody fusion (OLIF). Chin J Neurosurg Dis Res, 2017, 16: $538-541$.

11. Zeng ZY, Xu ZW, He DW, et al. Complications and Prevention Strategies of Oblique Lateral Interbody Fusion Technique. Orthop Surg. 2018;10(2):98106.

12. Zhao Q, Zhang H, Hao D, Guo H, Wang B, He B. Complications of percutaneous pedicle screw fixation in treating thoracolumbar and lumbar fracture. Medicine (Baltimore). 2018;97(29):e11560.

13. Gazzeri R. Percutaneous Pedicle Screw Fixation Technique in the Thoracic and Lumbar Spine-Tips and Tricks. Surg Technol Int. 2016;28:303-310.

14. Aitken RC. Measurement of feelings using visual analogue scales. Proc R Soc Med. 1969;62(10):989-993.

15. Fairbank JC, Couper J, Davies JB, O'Brien JP. The Oswestry low back pain disability questionnaire. Physiotherapy. 1980;66(8):271-273.

16. Bridwell KH, Lenke LG, McEnery KW, et al. Anterior fresh frozen structural allografts in the thoracic and lumbar spine. Do they work if combined with posterior fusion and instrumentation in adult patients with kyphosis or anterior column defects?. Spine (Phila Pa 1976). 1995;20(12):1410-1418.

17. Tohmeh AG, Khorsand D, Watson B, et al. Radiographical and clinical evaluation of extreme lateral interbody fusion: effects of cage size and instrumentation type with a minimum of 1-year follow-up. Spine (Phila Pa 1976). 2014;39(26):E1582-E1591.

18. Xu DS, Walker CT, Godzik J, Turner JD, Smith W, Uribe JS. Minimally invasive anterior, lateral, and oblique lumbar interbody fusion: a literature review. Ann Transl Med. 2018;6(6):104.

19. Liu L, Liang Y, Zhang H, et al. Imaging Anatomical Research on the Operative Windows of Oblique Lumbar Interbody Fusion:[J]. Plos One, 2016, 11(9):e0163452.

20. Zairi F, Sunna T P, Westwick H J, et al. Mini open oblique lumbar interbody fusion (OLIF) approach for multi-level discectomy and fusion involving L5-S1: Preliminary experience[J]. Orthop Traumatol Surg Res, 2017, 103(2).

21. Li HM, Zhang RJ, Shen CL. Radiographic and Clinical Outcomes of Oblique Lateral Interbody Fusion Versus Minimally Invasive Transforaminal Lumbar Interbody Fusion for Degenerative Lumbar Disease. World Neurosurg. 2019;122:e627-e638.

22. Guo HZ, Tang YC, Guo DQ, et al. Stability Evaluation of Oblique Lumbar Interbody Fusion Constructs with Various Fixation Options: A Finite Element Analysis Based on Three-Dimensional Scanning Models. World Neurosurg. 2020;138:e530-e538.

23. St Clair S, Tan JS, Lieberman I. Oblique lumbar interbody fixation: a biomechanical study in human spines. J Spinal Disord Tech. 2012;25(4):183189.

24. He W, He D, Sun Y, et al. Quantitative analysis of paraspinal muscle atrophy after oblique lateral interbody fusion alone vs. combined with percutaneous pedicle screw fixation in patients with spondylolisthesis. BMC Musculoskelet Disord. 2020;21(1):30. Published 2020 Jan 14.

25. Li R, Li X, Zhou H, Jiang W. Development and Application of Oblique Lumbar Interbody Fusion. Orthop Surg. 2020;12(2):355-365.

26. Wang YP, An JL, Sun YP, et al. Comparison of outcomes between minimally invasive transforaminal lumbar interbody fusion and traditional posterior lumbar intervertebral fusion in obese patients with lumbar disk prolapse. Ther Clin Risk Manag. 2017;13:87-94. Published 2017 Jan 19.

27. Calvo-Echenique A, Cego?ino J, Chueca R, et al. Stand-alone lumbar cage subsidence: A biomechanical sensitivity study of cage design and placement. Comput Methods Programs Biomed. 2018;162:211-219.

28. Palepu V, Helgeson M, Molyneaux-Francis M, et al. THE EFFECTS OF BONE MICROSTRUCTURE ON SUBSIDENCE RISK FOR ALIF, LLIF, PLIF, AND TLIF SPINE CAGES [published online ahead of print, 2018 Dec 5]. J Biomech Eng. 2018;10.1115/1.4042181.

29. Tian L, Yang R, Wei L, et al. Prevalence of osteoporosis and related lifestyle and metabolic factors of postmenopausal women and elderly men: A cross-sectional study in Gansu province, Northwestern of China. Medicine (Baltimore). 2017;96(43):e8294.

30. Yan G, Huang Y, Cao H, et al. Association of breastfeeding and postmenopausal osteoporosis in Chinese women: a community-based retrospective study. BMC Womens Health. 2019;19(1):110.

31. Oh KW, Lee JH, Lee JH, et al. The Correlation Between Cage Subsidence, Bone Mineral Density, and Clinical Results in Posterior Lumbar Interbody Fusion. Clin Spine Surg. 2017;30(6):E683-E689.

\section{Figures}



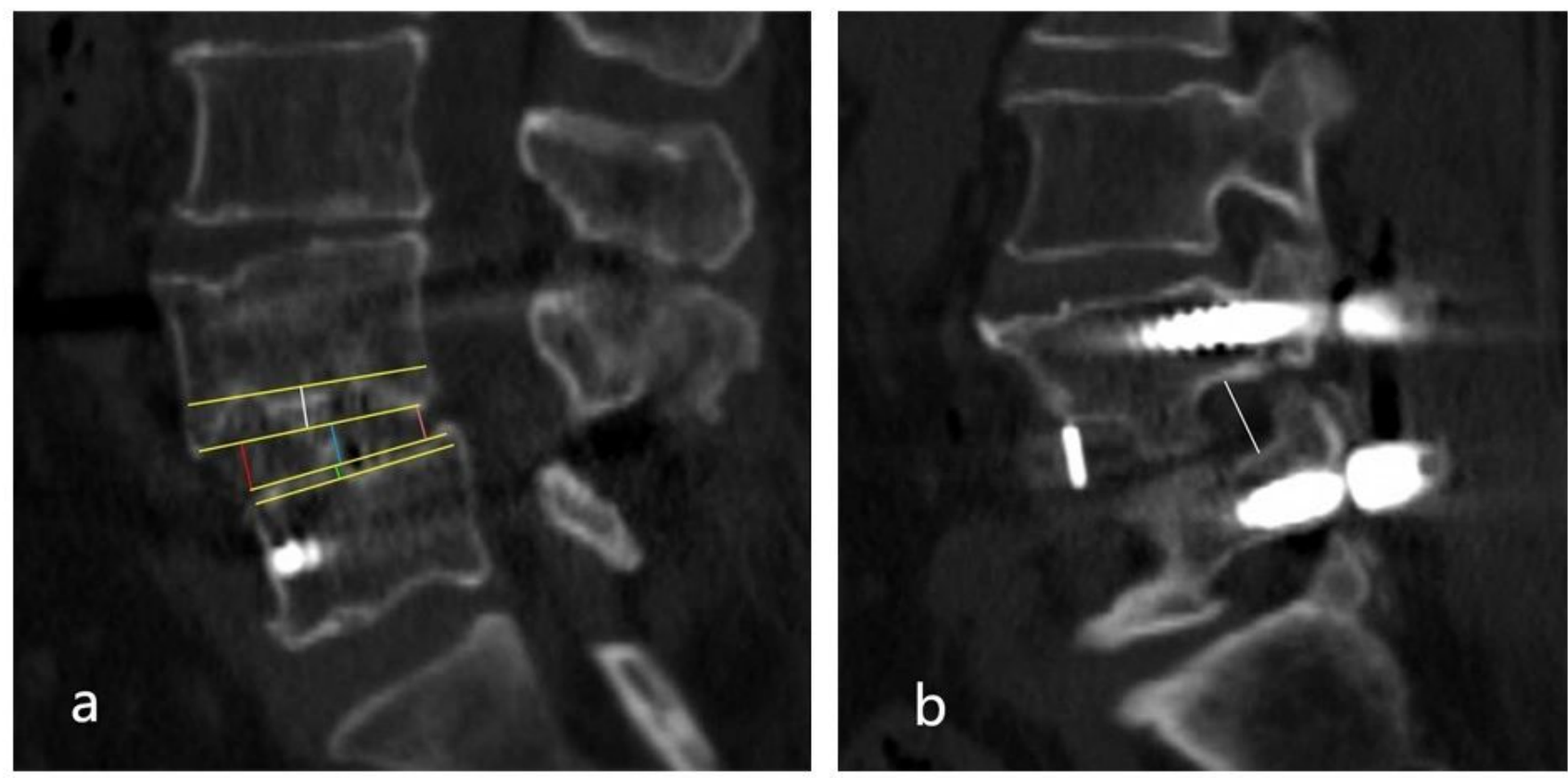

Figure 1

Measurement of radiological parameters: (a) the boundary of the endplate and the cage is delineated by yellow line. The tCS is defined as the sum of the cephalic CS (white line) and caudal CS (green line), and mCS is the larger one in them. DH is defined as the mean of the anterior DH (red line), middle DH (blue line) and posterior $\mathrm{DH}$ (pink line). (b) FH is measured by the perpendicular from the lower edge of the cephalic vertebra pedicle to the upper edge of the caudal vertebra pedicle. $\mathrm{FH}$ is the mean value of bilateral $\mathrm{FH}$.
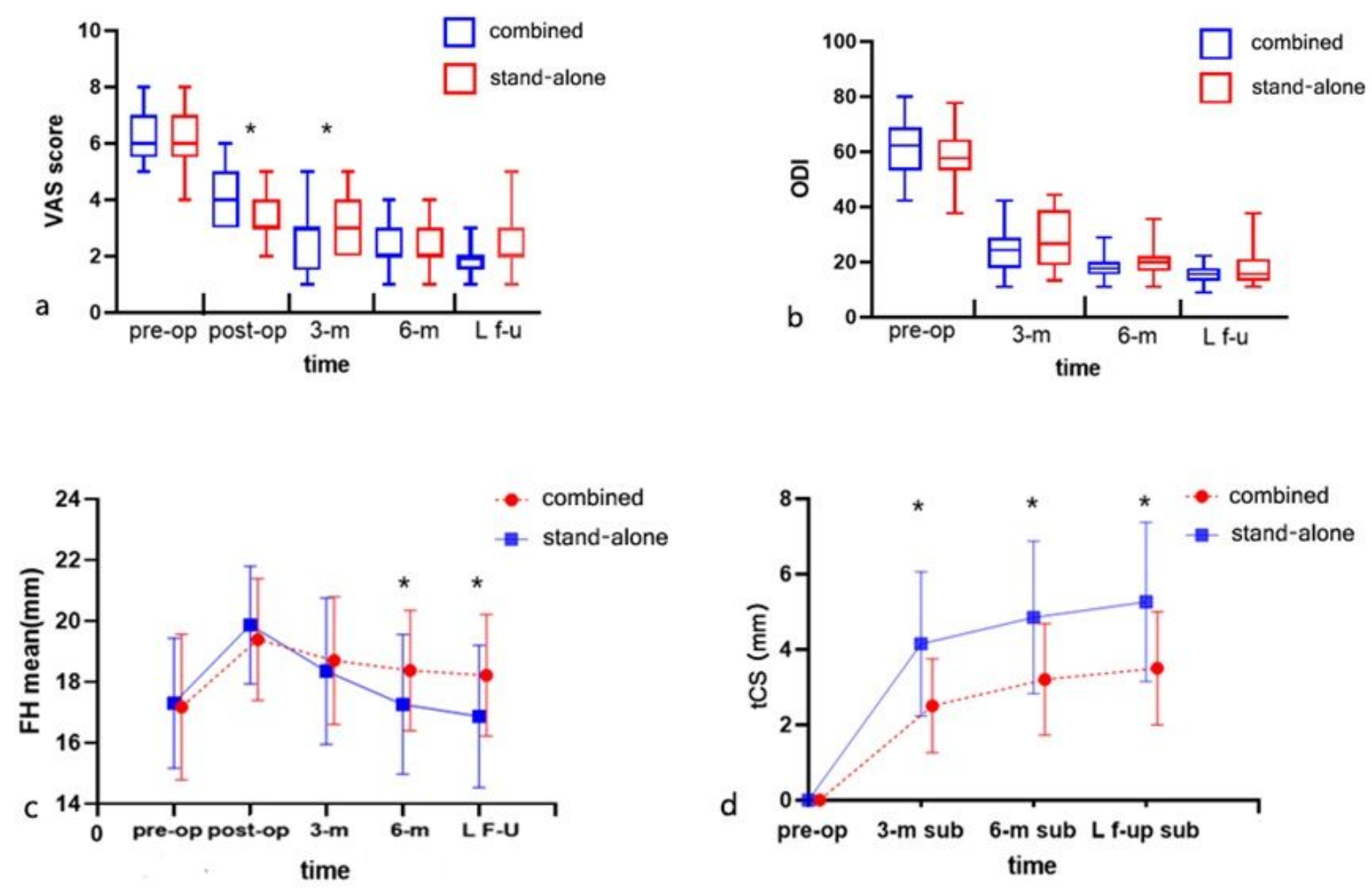

Figure 2

The clinical and radiological results of the two groups. (a) VAS comparison between groups. (b) ODI comparison between groups. (c) FH at each time point of the two groups. (d) tCS at each time point of the two groups. $\otimes$ The difference was statistically significant $(p<0.05)$ 